\title{
Effect of Sorbus commixta on the invasion and migration of human hepatocellular carcinoma Hep3B cells
}

\author{
HYERIN PARK $^{1,2}$, HYUNWOOK PARK ${ }^{3}$, TAE-WOOK CHUNG ${ }^{2}$, HEE-JUNG CHOI $^{2}$, \\ YEON-SEOP JUNG ${ }^{4}, \mathrm{SYNG}^{-O O K ~ \mathrm{LEE}^{4} \text { and KI-TAE HA }}{ }^{1,2}$ \\ ${ }^{1}$ School of Korean Medicine and ${ }^{2}$ Korean Medical Research Center for Healthy Aging, Pusan National University, \\ Yangsan, Gyeongnam-do 626-870, Republic of Korea; ${ }^{3}$ Department of Chemistry, Georgetown University, \\ Washington, DC 20057, USA; ${ }^{4}$ Department of Food Science and Technology, \\ Keimyung University, Daegu 42601, Republic of Korea
}

Received November 26, 2015; Accepted May 18, 2017

DOI: $10.3892 / \mathrm{ijmm} .2017 .3010$

\begin{abstract}
Tumor metastasis is a main cause of cancer-related morbidity and mortality. Thus, a number of medicinal herbs and phytochemicals have been investigated as possible candidates for the inhibition of cancer metastasis. Sorbus commixta Hedl. (SC) is a traditional medicinal plant used in the treatment of inflammatory diseases, as it has antioxidant, anti-inflammatory, anti-atherosclerotic and anti-hepatotoxic activities. In this study, we demonstrate that the water extract of SC exerts inhibitory effect on the invasion and migration of hepatocellular carcinoma Hep3B cells. The activity and expression of matrix metalloproteinase (MMP)-9, which is responsible for the invasion of cancer cells, was decreased by SC treatment. The invasive and migratory potentials of the Hep3B cells were also decreased, as evidence by in vitro assay using the Boyden chamber system. In addition, the expression of the chemokine receptors, C-X-C chemokine receptor type 4 (CXCR) 4 and C-X-C chemokine receptor type 6 (CXCR6), were inhibited by $\mathrm{SC}$ in Hep3B cells. Furthermore, actin fiber organization was markedly suppressed by SC treatment. Taken together, the findings of this study suggest for the first time, to the best of our knowledge, that SC suppresses the invasion and migration of highly metastatic Hep3B cells.
\end{abstract}

\section{Introduction}

Frequent metastasis is the main cause of cancer-related recurrence and mortality, including hepatocellular carcinoma (HCC) $(1,2)$.

Correspondence to: Professor Ki-Tae Ha, School of Korean Medicine, Pusan National University, Busandaehak-ro 49, Mulgeum-eup, Yangsan, Gyeongsangnam-do, Republic of Korea

Email: hagis@pusan.ac.kr

Key words: Sorbus commixta, invasion, migration, matrix metalloproteinase-9, C-X-C chemokine receptor type 4, C-X-C chemokine receptor type 6 , cytoskeleton
The metastatic processes of cancer consists of complex steps, i.e., the invasion of cancer into tissues around the primary sites, entry into vascular or lymphatic systems, survival in the bloodstream, adhesion onto vascular endothelial cells in small vessels around new tissues, extravasation from the circulation into surrounding tissues, and finally growth, to form migrated tumors in new sites (3-5). Thus, in order to prevent and treat cancer metastasis, researchers are trying to understand the molecular mechanisms responsible for cancer metastasis and to develop novel and effective anti-metastatic drug candidates $(4,6)$.

A number of medicinal herbs and phytochemicals have been reported as potent candidates for anti-metastatic drugs (7-9). Sorbus commixta Hedl. (Rosaceae) (SC) is a traditional medicinal plant used in the treatment of inflammatory diseases, such as asthma, bronchitis, gastritis and edema $(10,11)$. Previously, SC was reported to have antioxidant $(12,13)$, anti-inflammatory $(11)$, anti-atherosclerotic (14-16) and anti-hepatotoxic activities (17). In addition, SC has been shown to inhibit the expression of matrix metalloproteinase (MMP)-1 (12) and tyrosine phosphatases activity (18), which are associated with the migration and development of cancer (19-21). However, the inhibitory effects of SC on cancer metastasis have not been reported to date, at least to the best of our knowledge.

In this study, we demonstrate that the water extract of SC inhibits the invasion and migration of the highly metastatic HCC cell line, Hep3B. The underlying mechanisms of the anti-invasive and anti-migratory effects of SC are associated with the inhibition of MMP-9 activity and expression, chemokine receptor expression, and actin filament arrangement. To the best of our knowledge, this is the first study to demonstrate that SC exerts anti-invasive and anti-migratory effects on HCC cells.

\section{Materials and methods}

Materials. Antibody to MMP-9 (AB18916) was supplied by Calbiochem (San Diego, CA, USA). Antibodies against phosphoextracellular signal regulated kinase (ERK; sc-7383), ERK2 (sc-154), p38 (sc-535), c-jun N-terminal kinase (JNK; sc-7345), p65 subunit of NF- $\mathrm{B}$ (p65; sc-50350), and glyceraldehyde 3-phosphate dehydrogenase (GAPDH; sc-32233) were provided 
by Santa Cruz Biotechnology, Inc. (Santa Cruz, CA, USA). Antibodies for phospho-p38 (\#9211), phospho-JNK (\#9255), and inhibitor of NF- $\kappa \mathrm{B}(\mathrm{I} \kappa \mathrm{B}$; \#9242) were supplied by Cell Signaling Technology (Danvers, MA, USA). Antibody against $\beta$-actin was purchased from Sigma-Aldrich (St. Louis, MO, USA). The antibodies for goat anti-mouse IgG (NCI1430KR) and goat anti-rabbit IgG (NCI1460KR) were provided by Thermo Fisher Scientific, Inc. (Waltham, MA,USA). All chemicals and reagents, including 3-(4,5-dimethylthiazol-2-yl)-2,5-diphenyltetrazolium bromide (MTT), lupenone, lupeol and prunetin, were obtained from Sigma-Aldrich unless indicated otherwise.

Extraction of SC. The stem and cortex of SC, which were grown and collected in Gyeongsangbuk-do province in Korea in 2012, were purchased from Omniherb Co. (Daegu, Korea) and authenticated by botanical expert analysis by the company. A voucher specimen is kept at the School of Korean Medicine, Pusan National University, Yangsan, Korea. The air-dried stem and cortex of SC $(50 \mathrm{~g})$ was cut and extracted with distilled water $(1 \mathrm{l})$ at $100^{\circ} \mathrm{C}$ for $4 \mathrm{~h}$. The extract was filtered with Whatman paper (6 $\mu \mathrm{m}$; Whatman PLC, Kent, UK) and concentrated using a rotary evaporator (Eyela, Tokyo, Japan). Subsequently, the extract was lyophilized using a freeze dryer (Labconco Corporation, Kansas city, MO, USA) to yield $3.1 \mathrm{~g}$ of powder (abbreviated as SC). The powder was dissolved in DMSO for stock solution $(100 \mathrm{mg} / \mathrm{ml})$ and diluted with culture medium prior to use in the experiments.

Cell culture and determination of cell viability. Hep3B, HepG2 HCC cells, Chang liver cells and HCT116 colon cancer cells were purchased from the American Type Culture Collection (ATCC; Rockville, MD, USA) and grown in Dulbecco's modified Eagle's medium (DMEM; Thermo Fisher Scientific, Inc.) supplemented with L-glutamine (200 mg/l), $10 \%(\mathrm{v} / \mathrm{v})$ heat-inactivated fetal bovine serum (FBS; Sigma-Aldrich), and antibiotics $(100 \mathrm{U} / \mathrm{ml}$ penicillin and $100 \mu \mathrm{g} / \mathrm{ml}$ streptomycin; Thermo Fisher Scientific, Inc.) in a humidified incubator at $37^{\circ} \mathrm{C}, 5 \% \mathrm{CO}_{2}$ prior to the experiments.

The cytotoxicity caused by SC was evaluated using an MTT assay. Briefly, the Hep3B cells were incubated in 24-well plates with the indicated concentrations of SC for $24 \mathrm{~h}$. Subsequently, MTT solution $(2.0 \mathrm{mg} / \mathrm{ml})$ was added to each well containing the cells. Following $4 \mathrm{~h}$ of incubation at $37^{\circ} \mathrm{C}$ and $5 \% \mathrm{CO}_{2}$ in a cell culture incubator, the conditioned medium was removed, and formazan crystals formed in living cells were estimated by measuring the absorbance at $540 \mathrm{~nm}$ using a microplate reader (SpectraMax M2; Molecular Devices LLC, Sunnyvale, CA, USA). The percentages of living cells were calculated against the control cells by dividing each of the absorbance values by the average of that from the control sample without treatment with SC.

Gelatin zymography assay. Gelatin zymography assay for detecting MMP-9 activity was performed according to a previously described method (22). For in vitro gelatinase activity assays, culture medium from the Hep3B cells was used for the source of enzyme. The cells were cultured in serum-free medium for $24 \mathrm{~h}$ and equal amounts of medium were resuspended in sample buffer containing $62.5 \mathrm{mM}$ Tris- $\mathrm{HCl}$ ( $\mathrm{pH} 6.8$ ), $10 \%$ glycerol, $2 \%$ SDS and $0.00625 \%$ (w/v) bromophenol blue, and then loaded without boiling in a $7.5 \%$ acrylamide/bisacrylamide (29.2:0.8) separating gel containing $0.1 \%(\mathrm{w} / \mathrm{v})$ gelatin. Electrophoresis was performed at a voltage of $100 \mathrm{~V}$ at $4^{\circ} \mathrm{C}$. Following electrophoresis, the gel was soaked twice in $0.25 \%$ Triton $\mathrm{X}-100$ for $30 \mathrm{~min}$ at room temperature and washed in pure distilled water. The gel slab was cut into slices corresponding to the lanes, and then placed into different tanks containing the indicated concentrations of SC, freshly solubilized in Tris-buffered saline. The gels were soaked in incubation buffer containing $50 \mathrm{mM}$ Tris- $\mathrm{HCl}(\mathrm{pH} 7.6)$, $20 \mathrm{mM} \mathrm{NaCl}, 5 \mathrm{mM} \mathrm{CaCl}_{2}$ and $0.02 \%$ Brij 58. The gels were incubated at $37^{\circ} \mathrm{C}$ for $18 \mathrm{~h}$ and then stained for $30 \mathrm{~min}$ in $0.1 \%$ (w/v) Coomassie blue R-250 (Sigma-Aldrich) solubilized in $30 \%$ methanol and $10 \%$ acetic acid.

For detecting gelatinase activity in the cell culture, Hep3B cells were grown in serum-free culture medium with the indicated concentrations of SC for $24 \mathrm{~h}$. The amount of secreted protein in the conditioned medium was estimated by cell numbers. Culture media were prepared in sample buffer mentioned above without boiling. The samples were loaded in an acrylamide/bisacrylamide (29.2:0.8) separating gel containing $0.1 \%(\mathrm{w} / \mathrm{v})$ gelatin, and then electrophoresed at $4^{\circ} \mathrm{C}$. The gels were washed twice in $0.25 \%$ Triton $\mathrm{X}-100$ for $30 \mathrm{~min}$ at room temperature and incubated at $37^{\circ} \mathrm{C}$ in incubation buffer same as the one mentioned above. Following incubation at $37^{\circ} \mathrm{C}$ for $18 \mathrm{~h}$, the gels were stained for $30 \mathrm{~min}$ in Coomassie blue R-250 staining solution. The stained gel was photographed and bands corresponding to the activity of MMP-9 were quantified using ImageJ software (NIH, Bethesda, MD, USA).

Reverse transcription-polymerase chain reaction (RT-PCR). To measure the changes in the mRNA expression levels related to tumor metastasis, Hep3B cells were treated with the indicated concentrations of SC $(0,50,100 \mu \mathrm{g} / \mathrm{ml})$ in serumfree DMEM, and incubated for $24 \mathrm{~h}$. Total RNA was extracted from the cells using TRIzol reagent (Invitrogen, Carlsbad, CA, USA; Bio-Rad Laboratories, Inc., Hercules, CA, USA). An equal amount of total RNA was used for the synthesis of cDNA using oligo-dT primer and AccuPower RT-PreMix (Bioneer Co., Daejeon, Korea). The cDNA was amplified by PCR with the following primers: MMP-9, 5'-AGTCCGGCA GACAATCCTTGCA-3' (sense) and 5'-ATCCACGCGAATG ACGCTCTGG-3' (antisense); C-X-C chemokine receptor CXCR4, 5'-AGCCTGTGGATGGTGGTGTTTC-3' (sense) and 5'-CCTTGCTTGATGACTCCCAAAAG-3' (antisense); CXCR6, 5'-TACGATGGGCACTACGAGGGAG-3' (sense) and 5'-GCAAAGA A ACCAACAGGGAGACCAC-3' (antisense); GAPDH, 5'-GGAGCCAAAAGGGTCATCAT-3' (sense) and 5'-GTGATGGCATGGACTGTGGT-3' (antisense). the amplification of the PCR reactions was performed with AccuPower PCR-PreMix (Bioneer Co.), under the following conditions: an initial denaturation at $95^{\circ} \mathrm{C}$ for $5 \mathrm{~min}$ followed by 30 cycles (for MMP-9 and GAPDH) or, 35 cycles (for CXCR4 and CXCR6) of denaturation for $40 \mathrm{sec}$ at $95^{\circ} \mathrm{C}$, annealing for $40 \mathrm{sec}$ at $60^{\circ} \mathrm{C}$ (for MMP-9 and GAPDH) or, $63^{\circ} \mathrm{C}$ (for CXCR4 and CXCR6) and extension for $50 \mathrm{sec}$ at $72^{\circ} \mathrm{C}$ with a final extension for $10 \mathrm{~min}$ at $72^{\circ} \mathrm{C}$. Amplified PCR products were separated on $1.0 \%$ agarose gels and visualized under UV light. Images were captured using the GelDoc-It TS imaging system (UVP, Upland, CA, USA). 
Western blot analysis. To examine the effect of SC on the regulation of protein expression related to tumor metastasis, we treated the cells with the indicated concentrations of SC $(0,50,100 \mu \mathrm{g} / \mathrm{ml})$ in serum-free DMEM, followed by incubation for $24 \mathrm{~h}$. Total proteins were extracted from the cells using RIPA buffer (Cell Signaling Technology) containing $1 \mathrm{mM}$ phenylmethylsulfonyl fluoride. The amounts of proteins were estimated using the Quick Start ${ }^{\mathrm{TM}}$ Bradford Protein assay (Bio-Rad Laboratories, Inc.). An equal amount $(20 \mu \mathrm{g})$ of protein from each sample was fractionated by sodium dodecyl sulfate-polyacrylamide gel electrophoresis (SDS-PAGE) and the protein was transferred by electrophoresis onto nitrocellulose membranes (Hybond ECL; GE Healthcare, Uppsala, Sweden). The membranes were blocked for $1 \mathrm{~h}$ with $5 \%$ non-fat dry milk at room temperature and incubated with primary antibodies specific for the target protein at $4^{\circ} \mathrm{C}$ overnight. The membranes were washed twice, and incubated with appropriate secondary antibodies conjugated with horseradish peroxidase. The specific bands of the proteins of interest were detected using ECL Plus (GE Healthcare).

Transwell invasion and migration assay. The filter inserts (8 $\mu \mathrm{m}$ pore size) that fit into 24 -well invasion chambers (Becton-Dickinson, Franklin Lakes, NJ, USA) were used for invasion and migration assays. For the invasion assay, the upper sides of the filters were coated with $100 \mu \mathrm{l}$ of $0.2 \%$ collagen-fragmented gelatin. Serum-free DMEM with or without SC (indicated concentrations) was added to the upper compartment of the chamber. In the lower part of the chamber, DMEM supplemented with $10 \%$ FBS was added. The chambers were incubated at $37^{\circ} \mathrm{C}$ for $24 \mathrm{~h}$ in a $5 \% \mathrm{CO}_{2}$ atmosphere. For the migration assay, serum-free DMEM with or without SC (indicated concentrations) was added to the upper part of the chamber. To the lower part of chamber, DMEM supplemented with $10 \%$ FBS was added to make a gradient of chemoattractive factors. The chambers were incubated at $37^{\circ} \mathrm{C}$ for $24 \mathrm{~h}$ in a $5 \% \mathrm{CO}_{2}$ atmosphere. Following incubation, the filter inserts from both of invasion or migration assay were removed from the chamber well, and the cells on the upper side of the filter membranes were removed using cotton swabs. The membranes were fixed, stained with hematoxylin and eosin (HHS16; Sigma-Aldrich), and mounted on microscope slide glasses. The cells located on the underside of the filters were counted for invaded or migrated cells.

F-actin staining and fluorescence microscopy. The Hep3B cells were seeded on sterilized $12 \mathrm{~mm} \pi$ rounded cover slides in 24-well culture plates, and treated with or without SC (indicated concentrations) for $24 \mathrm{~h}$. The cells were washed with phosphate-buffered saline (PBS) and fixed in $3.7 \%$ formalin for $10 \mathrm{~min}$. The cells were washed with PBS, and then permeabilized with $0.1 \%$ Triton X-100 in PBS. For actin staining, the cells were washed with PBS, and then incubated with PBS including $1 \mathrm{U}$ of Texas Red-X phalloidin (Invitrogen) for $30 \mathrm{~min}$ at room temperature. The cells were washed with PBS again, and were then analyzed using a confocal microscope (Axio Observer Z1; Carl Zeiss, Oberkochen, Germany).

Statistical analysis. The values from the cell viability, gelatin zymography, invasion and migration assays were calculated by the percentage of control cells and expressed as the means $\pm \mathrm{SD}$. The differences between the mean values compared with the control group were evaluated by one-way analysis of variance (ANOVA) with a post hoc Dunnett's comparison. The minimum level of significance was set at a P-value of 0.05 for all the analyses. All the experiments were independently carried out at least 3 times.

\section{Results}

Cytotoxic effects of SC on Hep3B cells. Initially, we examined the cytotoxic effects of SC on several cell lines, such as Hep3B, HepG2, Chang and HCT116 cell, in order to determine the optimal concentration for use in subsequent experiments. SC exerted a significant cytotoxic effect on the Hep3B cells at $250 \mu \mathrm{g} / \mathrm{ml}$. In addition, SC significantly inhibited the growth of HepG2 HCC cells from the concentration of $200 \mu \mathrm{g} / \mathrm{ml}$, and that of the HCT116 colorectal cancer cells from the concentration of $100 \mu \mathrm{g} / \mathrm{ml}$. In addition, $\mathrm{SC}$ significantly attenuated the growth of Chang cells from the concentration of $500 \mu \mathrm{g} / \mathrm{ml}$. SC $(250 \mu \mathrm{g} / \mathrm{ml})$ suppressed the growth of Chang cells, although no significant differences were observed (Fig. 1). Among the liver cancer cell lines, the Hep3B cells exhibit the most potent invasive and migratory potential (23). Thus, we examined the inhibitory effects of $\mathrm{SC}$ on the invasion and migration of liver cancer cells using the Hep3B cells and SC at up to a concentration of $100 \mu \mathrm{g} / \mathrm{ml}$.

$S C$ inhibits the activity and expression of MMP-9. We then examined the effects of SC on the activity and expression of MMP-9. The results from in vitro gelatin zymography assay revealed that SC significantly inhibited enzyme activity from the concentration of $50 \mu \mathrm{g} / \mathrm{ml}$ (Fig. 2A). In addition, when $\mathrm{SC}$ was added to the cell culture medium of Hep3B cells, the activity of MMP-9 was also decreased (Fig. 2B). These results suggested that the expression level of MMP-9 was reduced by SC treatment. Thus, we confirmed the expression of MMP-9 using RT-PCR and western blot analysis. The results revealed that the mRNA and protein levels of MMP-9 were decreased at the concentration of $100 \mu \mathrm{g} / \mathrm{ml}$ (Fig. 2C and D).

$S C$ decreases the invasive and migratory potential of Hep3B cells. As MMP-9 is a major enzyme responsible for the destruction of extracellular matrix, an initial step of cancer metastasis $(24,25)$, we examined the effects of SC on the invasive property of Hep3B cells. The results from invasion assay using collagen-degraded gelatin as a substrate demonstrated that SC significantly reduced the numbers of invading Hep3B cells (Fig. 3). We then evaluated the effects of SC on the migratory activity of Hep3B cells using Boyden chamber assay. FBS was added to the lower chamber for making a chemoattractant gradient. The results revealed that SC significantly inhibited the migratory ability of the Hep3B cells in a dosedependent manner (Fig. 4).

$S C$ decreases the expression of chemokine receptors and arrangement of actin filament. Chemokine receptors expressed on the surface of cancer cells, particularly CXCR4 and CXCR6, play important roles in tumor metastasis $(26,27)$. Thus, we examined the expression of CXCR4 and CXCR6 in Hep3B cells. 

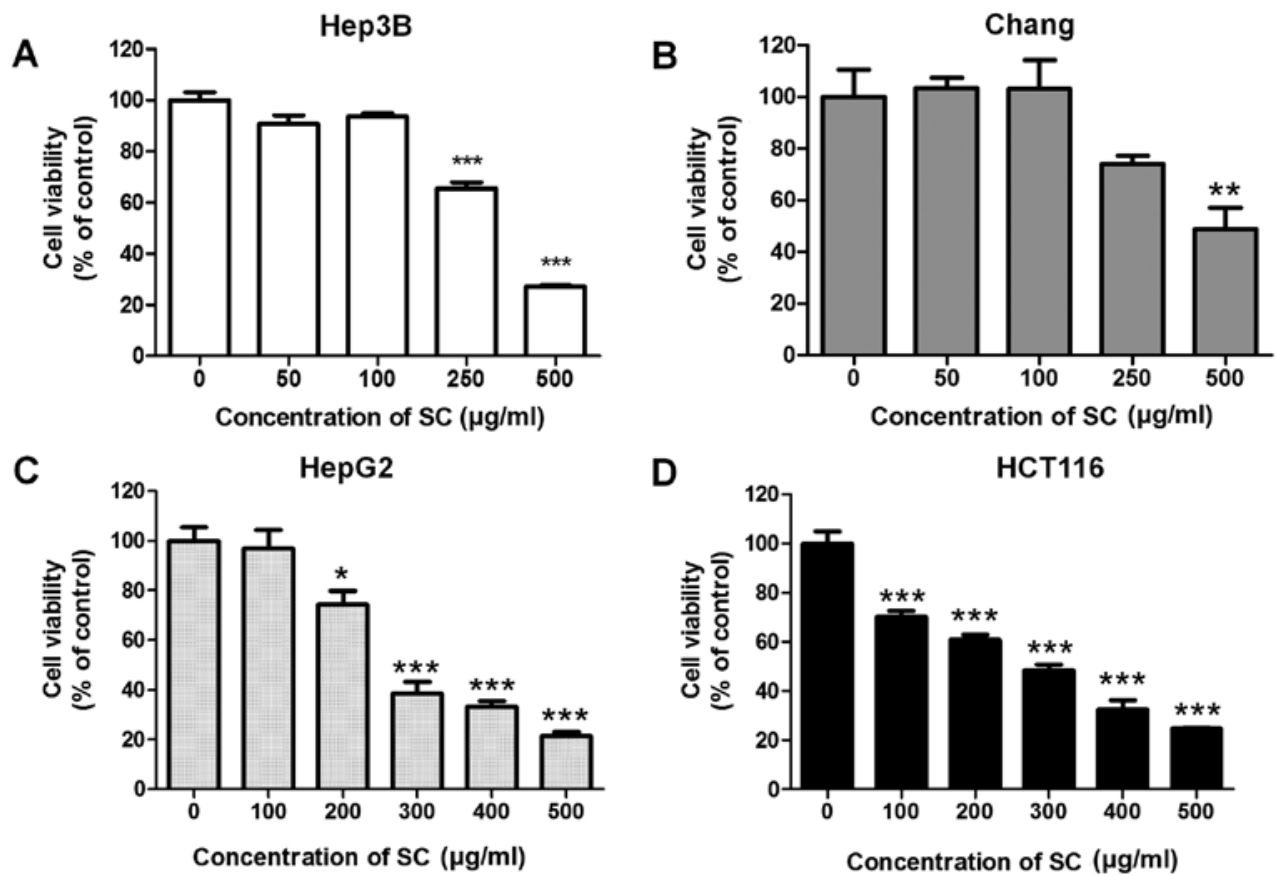

Figure 1. Cytotoxicity of Sorbus commixta (SC) on Hep3B, HepG2, Chang and HCT116 cells. (A-D) The cells were treated with the indicated concentrations of SC for $24 \mathrm{~h}$. Cell viability was evaluated by 3-(4,5-dimethylthiazol-2-yl)-2,5-diphenyltetrazolium bromide (MTT) assay. The results from 3 independent experiments are shown as the means $\pm \mathrm{SD} .{ }^{*} \mathrm{P}<0.05,{ }^{* *} \mathrm{P}<0.01$ and ${ }^{* * * *} \mathrm{P}<0.001$ compared to the control.
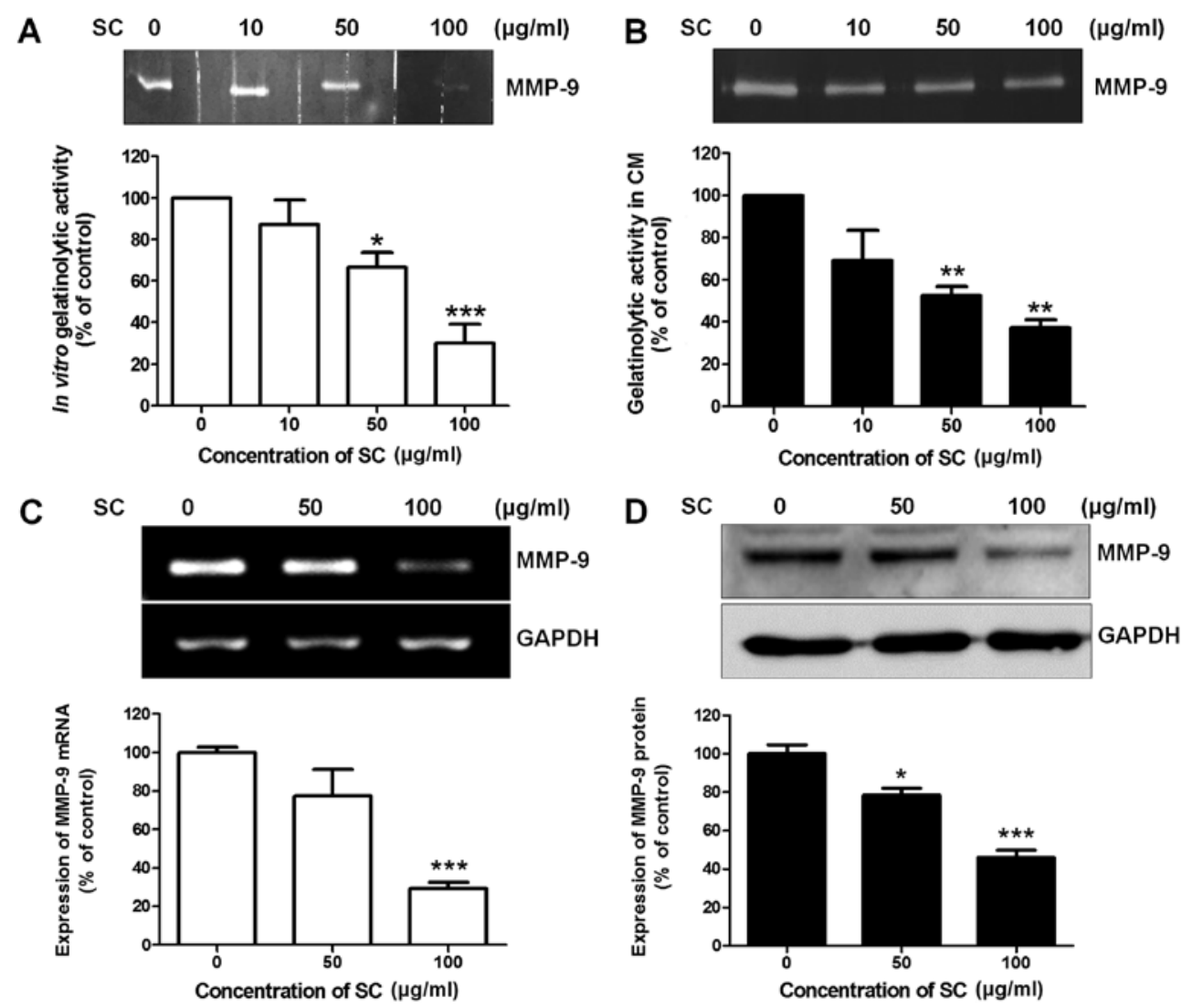

Figure 2. Inhibitory effect of Sorbus commixta (SC) on the activity and expression of MMP-9 in Hep3B cells. (A) In vitro gelatin zymography assay was performed using the culture medium of Hep3B cells as a source of enzyme. Indicated concentrations of SC were added into incubation buffer. Densitometric results of the bands are presented as the means $\pm \mathrm{SD}$ of 3 independent experiments. ${ }^{*} \mathrm{P}<0.05$ and ${ }^{* * *} \mathrm{P}<0.001$ compared to the control. (B) Hep3B cells were cultured in medium containing the indicated concentrations of SC for $24 \mathrm{~h}$. The same amounts of the culture medium were analyzed by zymography for gelatinolytic activity. Densitometric data of the bands were shown as the means \pm SD of 3 independent experiments. ${ }^{* *} \mathrm{P}<0.01$ compared to the control. (C and D) Hep3B cells were treated with the indicated concentrations of SC for $24 \mathrm{~h}$. RT-PCR and westen blot analysis were performed to evaluate the expression of matrix metalloproteinase (MMP)-9. Densitometric results of the bands are presented as the means \pm SD of 3 independent experiments. ${ }^{*} \mathrm{P}<0.05$ and ${ }^{* * *} \mathrm{P}<0.001$ compared to the control. 
A
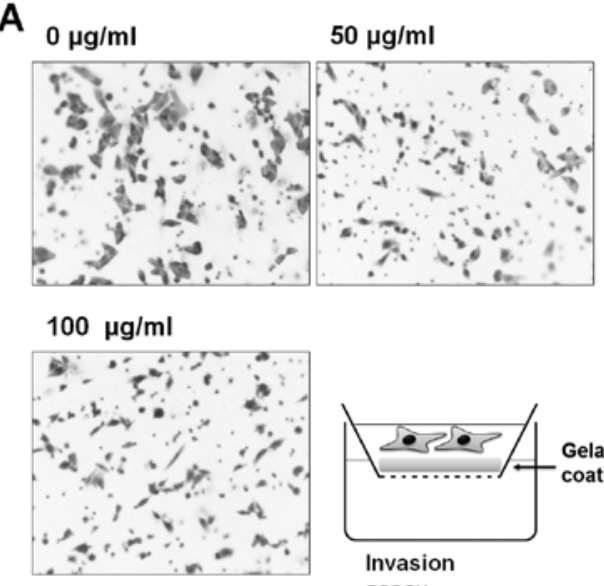

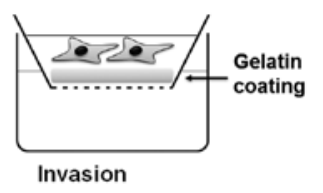

B

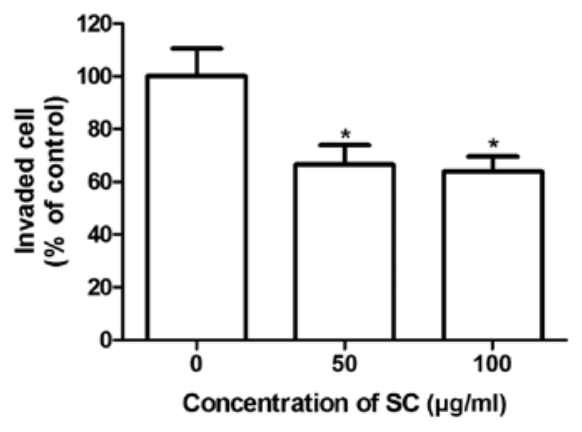

Figure 3. Inhibitory effect of Sorbus commixta (SC) on the invasion of Hep3B cells. Hep3B cells were seeded in a gelatin-coated upper chamber and incubated in medium containing the indicated concentrations of SC for $24 \mathrm{~h}$. The lower part of the membrane was stained with hematoxlyin and eosin (H\&E). (A) Representative images and (B) counted results are shown. The data demonstrated as the means \pm SD of 3 independent measurements. ${ }^{*} \mathrm{P}<0.05$ compared to the control.

A

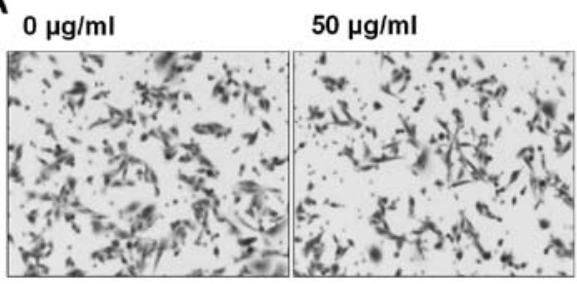

$100 \mu \mathrm{g} / \mathrm{ml}$

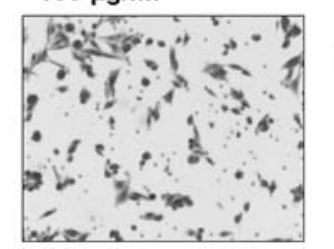

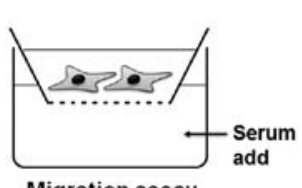

Migration assay
B

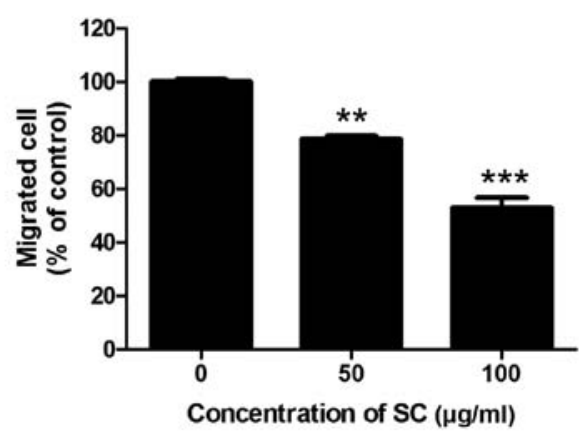

Figure 4. Inhibitory effect of Sorbus commixta (SC) on the migration of Hep3B cells. Hep3B cells were seeded in the upper chamber and incubated in serum-free medium containing the indicated concentrations of SC. The serum was added to the medium of the lower chamber. After $24 \mathrm{~h}$, the membrane was stained with hematoxlyin and eosin (H\&E). (A) Representative pictures were acquired using a microscope and (B) migrated cells were counted. The results are shown as the means \pm SD. ${ }^{* *} \mathrm{P}<0.01$ and ${ }^{* * *} \mathrm{P}<0.001$ compared to the control.

The results demonstrated that $\mathrm{SC}$ decreased the expression of CXCR4 and CXCR6 (Fig. 5A). In addition, the results from fluorescence microscopic observation revealed that $\mathrm{SC}$ suppressed actin filament rearrangement (Fig. 5B). These data suggest that the inhibitory effects of SC on the migratory activity of the Hep3B cells may be due to reduction in chemokine receptor expression and the suppression of actin filament polymerization.

SC inhibits the phosphorylation of ERK and p38. To determine which molecular signaling pathways are involved in the inhibitory effects of SC on the invasion and migration of Hep3B cells, the activation of nuclear factor- $\kappa \mathrm{B}(\mathrm{NF}-\kappa \mathrm{B})$ and mitogen-activated protein kinases (MAPKs) was examined. The results from western blot analysis revealed that the phosphorylation levels of ERK and p38 MAPKs were decreased by $\mathrm{SC}$ treatment at the concentration of 50 and $100 \mu \mathrm{g} /$ $\mathrm{ml}$. However, the phosphorylation level of JNK was slightly increased by SC treatment (Fig. 6A). In addition, treatment with SC did not affect on the protein levels of inhibitor of $\kappa \mathrm{B}(\mathrm{I} \kappa \mathrm{B})$ and the p65 subunit of NF- $\kappa \mathrm{B}$ (Fig. 6B). These results suggested that the ERK and p38 signaling pathways may be involved in the expression of the molecules involved in the invasion and migration of Hep3B cells.

\section{Discussion}

The process of cancer metastasis is composed of multiple sequential steps, such as invasion, intravasation, survival in the circulation, extravasation and growth in newly metastatic sites $(3,4)$. As metastasis is one of most prevalence causes of cancer-related mortality, many researchers have aimed to develop drugs able to suppress the metastatic potential of cancer cells, including HCC $(6,28)$. A number of natural products, such as baicalein from Scutellaria baicalensis (29), ardipusilloside from Ardisia pusilla (30), shikonin from Lithospermim erythrorhizon (31), acacetin from Robinia pseudoacacia (32) and caffeic acid phenethyl ester from propolis (33) have been reported to effectively inhibit the invasion and metastasis of HCC. 
A sc

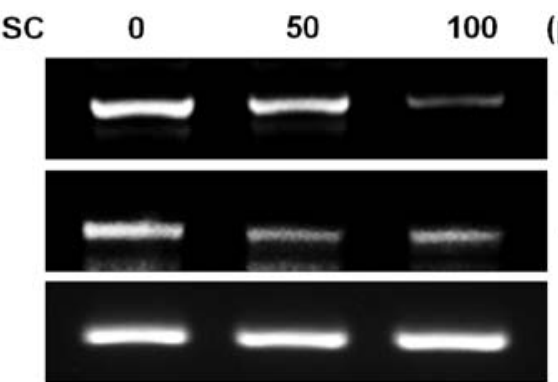

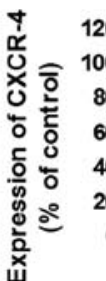
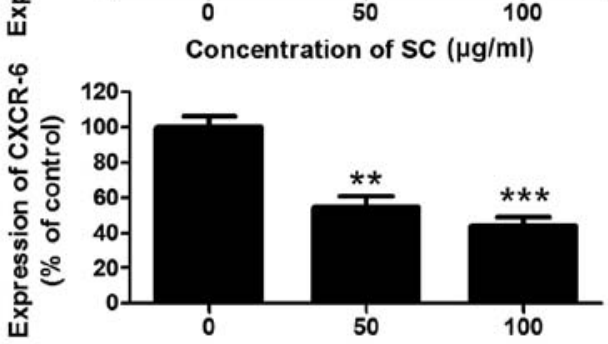

Concentration of SC $(\mu \mathrm{g} / \mathrm{ml})$

B

$0 \mu \mathrm{g} / \mathrm{ml}$

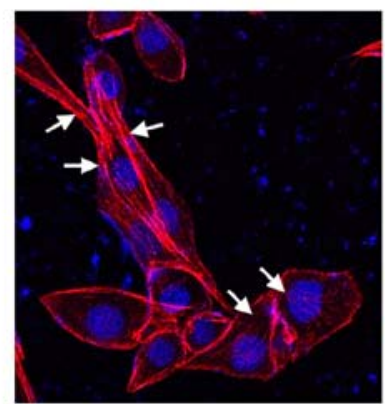

$100 \mu \mathrm{g} / \mathrm{ml}$
$50 \mu \mathrm{g} / \mathrm{ml}$
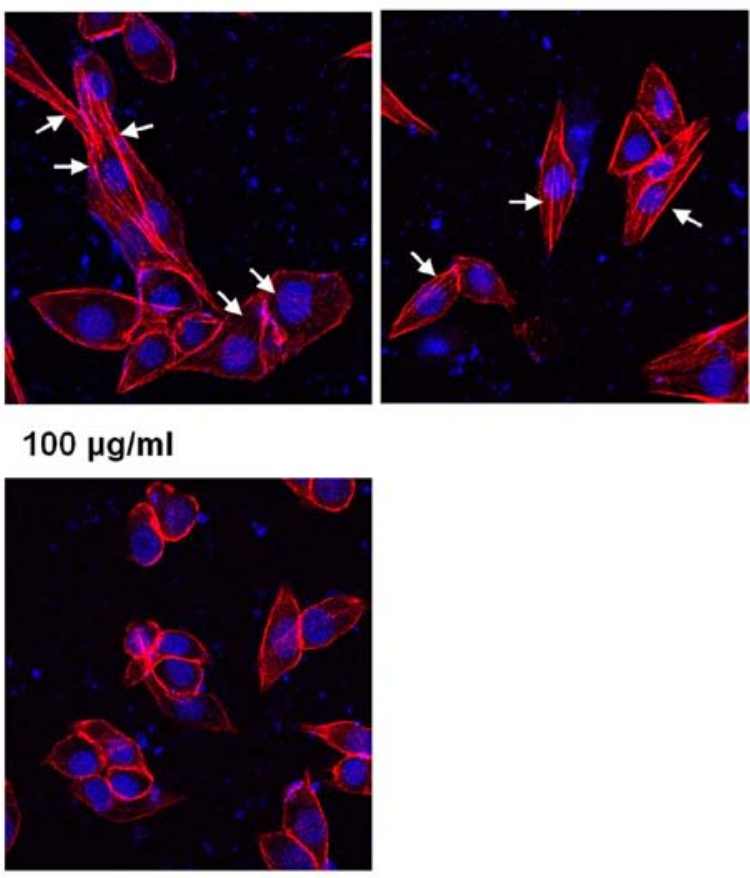

Figure 5. Inhibitory effect of Sorbus commixta (SC) on the expression of chemokine receptors and actin arrangement. (A) Hep3B cells were treated with the indicated concentrations of SC for $24 \mathrm{~h}$. The expression levels of CXCR4 and CXCR6, were measured by RT-PCR. Densitometric results of the bands are presented as the means $\pm \mathrm{SD}$ of 3 independent experiments. ${ }^{* *} \mathrm{P}<0.01$ and ${ }^{* * * *} \mathrm{P}<0.001$ compared to the control. (B) Hep3B cells were incubated in medium containing the indicated concentrations of SC for $24 \mathrm{~h}$ were fixed, stained with Texas Red-X phalloidin, and mounted with DAPI-containing solution. Images of stained cells were captured using a fluorescence microscope. Activated F-actin filaments are indicated by arrows.

A

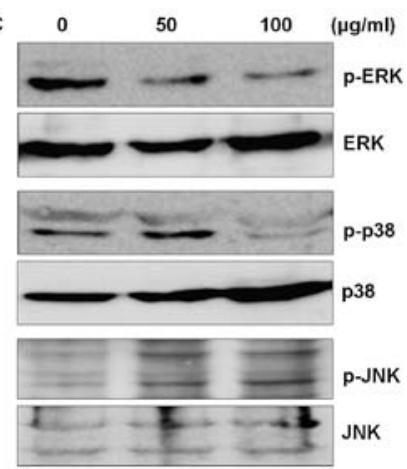

C

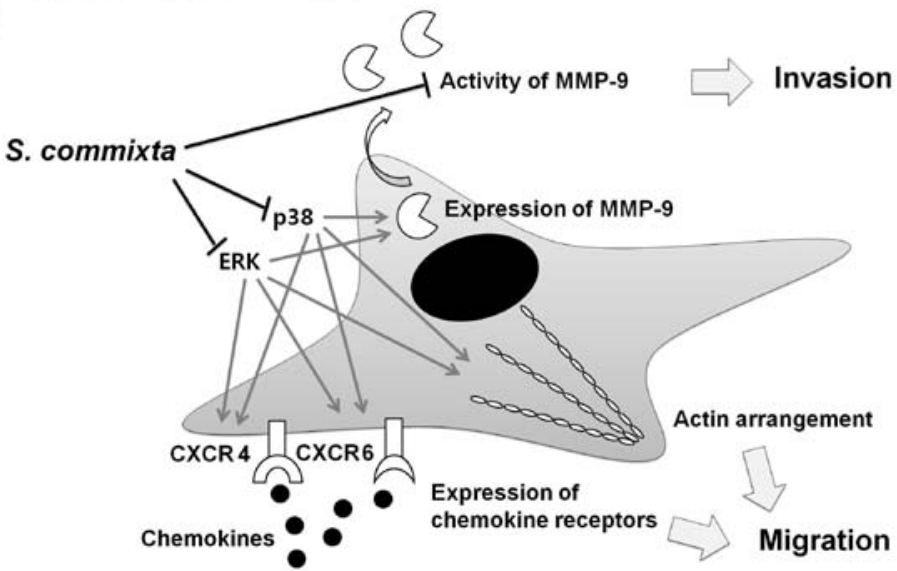

Figure 6. Inhibitory effect of Sorbus commixta (SC) on the activation of mitogen-activated protein kinase (MAPK) and nuclear factor- $\mathrm{kB}$ (NF-kB) pathways. Hep3B cells were treated with the indicated concentrations of SC for $24 \mathrm{~h}$. The activation of (A) MAPKs and (B) NF-kB pathways was examined by western blot analysis. (C) Schematic representation of the effect of SC on the invasion and migration of Hep3B cells and the underlying mechanism are presented. 
MMP-9 is an enzyme which plays a role in the process of tumor metastasis, as it is expressed in many types of cancer and can degrade type IV collagen, a major component of the basement membrane $(25,34)$. In addition, MMP-9 was recently reported as a modulator of signaling pathways that are involved in cell growth, migration and angiogenesis in a non-enzymatic manner $(24,35)$. In our ongoing efforts to identify a novel MMP-9 inhibitor from medicinal herbs, we successfully identified the water extract of SC as an inhibitor of the enzymatic activity of MMP-9 using in vitro gelatin zymography (Fig. 2A). In addition, SC decreased the secretion and expression of MMP-9 in Hep3B cells at a non-toxic concentration (Fig. 2B, C and D). Furthermore, the results from Transwell invasion assay clearly indicated that SC inhibited the invasive potential of Hep3B cells (Fig. 3). As shown in our previous study (36), the knockdown of MMP-9 expression using siRNA was sufficient to reduce the invasive ability of Hep3B cells. These results suggest that SC has an inhibitory effect on the invasiveness of Hep3B cells bg suppressing the expression and enzymatic activity of MMP-9.

We then further examined the effects of SC on the migration of Hep3B cells using Boyden chamber migration assay. As shown in Fig. 4, SC reduced the migratory ability of Hep3B cells. The cell surface receptors for chemokines highly expressed in various types of cancer, including HCC, such as CXCR4 and CXCR6, are known to play principle roles in cancer metastasis, particularly in the extravasation of tumor cells $(26,27)$. Thus, in this study, we examined the expression of CXCR4 and CXCR6 in SC-treated HCC cells. The expression levels of CXCR4 and CXCR6 were decreased by SC treatment in a dose-dependent manner, as evaluated by RT-PCR (Fig. 5A). In previous studies, CXCR4 and CXCR6 have been reported as regulators of cytoskeleton arrangement (37-39). In addition, cytoskeleton arrangement is responsible for the motility of cancer cells (4). Therefore, in this study, we examined whether SC affects actin organization in Hep3B cells. The results shown in Fig. 5B demonstrate that SC markedly reduced stress fiber and lamellipodia formation responsible for the migration of cells.

In previous studies, the extract of $\mathrm{SC}$ was shown to act as an anti-inflammatory agent by blocking the nuclear translocation of NF- $\kappa \mathrm{B}$ and its upstream pathways, such as phosphoinositide 3-kinase (PI3K) and Akt, in RAW 264.7 macrophage-like cells and vascular tissues of rats $(11,14)$. The signaling pathways such as NF- $\kappa \mathrm{B}$ and PI3K/Akt are also related with the expression of MMP-9 $(33,34)$ and CXCR4 $(40,41)$. In addition,PI3K/Akt is one of most essential pathways responsible for Rho-kinase activation and actin filament arrangement (42). Thus, we assumed that the inhibitory effects of SC on the expression of MMP-9 and CXCR4, and the arrangement of the actin cytoskeleton may be due to the suppression of the $\mathrm{NF}-\kappa \mathrm{B}$ and PI3K/Akt signaling pathways. However, our results clearly demonstrated that SC did not suppress the activation of $N F-\kappa B$ in Hep3B cells (Fig. 6B). This disagreement may be due to the different cell type or external stimuli used. On the other hand, SC inhibited the phosphorylation of ERK and p38, but not that of JNK (Fig. 6A). These signaling pathways, including p38 and ERK, are also involved in the expression of MMP-9 $(34,43)$, CXCR4 and CXCR6 (44,45). In addition, previous studies have revealed that F-actin re-arrangement is also regulated by the p38 or ERK signaling pathways $(46,47)$. Therefore, we suggest that the suppression of these molecules, which are involved in migration of tumor cells, may be mainly regulated by the p38 and ERK pathways.

Furthermore, the methanol extract of SC has been shown to reduce the expression of adhesion molecules, including ICAM-1, VCAM-1 and E-selectin, in the aortas of rats with atherosclerosis induced by fructose (14). As these molecules are also responsible for the adhesion of cancer onto vascular epithelial cells $(2,4)$, it is possible that SC inhibits the metastatic potential through the inhibition of these adhesion molecules. The metastasis of cancer is the main cause of cancer-associated mortality of most cancer patients (28). Therefore, the prevention of tumor metastasis has been the most important challenge in the development of anticancer drugs (48). Recently, many medicinal herbs and natural products have been discovered to have antimetastatic activities and many researchers have focused on developing novel candidates for anti-metastatic agents $(49,50)$.

In conclusion, in this study, and to the best of our knowledge, we are the first to demonstrate that SC suppresses the invasive and migratory potential of Hep3B cells through the inhibition of MMP-9, CXCR and cytoskeleton arrangement. The ERK and $\mathrm{p} 38$ signaling pathways may be involved in the inhibitory effects of SC on the invasive and migratory properties of Hep3B cells (Fig. 6C). From these results, we suggest that SC may be a potential candidate for drug development to inhibit tumor metastasis, particularly invasion, intravasation and the extravasation of cancer cells in multiple steps of cancer metastasis. Further extensive studies to determine the efficacy and safety of SC in in vivo experiments are required.

\section{Acknowledgements}

The present study was supported by the National Research Foundation of Korea (NRF) grant funded by the Ministry of Science, ICT and Future Planning (MISP), Korea government (grant no. 2014R1A5A20009936).

\section{References}

1. Bruix J, Gores GJ and Mazzaferro V: Hepatocellular carcinoma: clinical frontiers and perspectives. Gut 63: 844-855, 2014.

2. Friedl $P$ and Alexander S: Cancer invasion and the microenvironment: plasticity and reciprocity. Cell 147: 992-1009, 2011.

3. Chaffer CL and Weinberg RA: A perspective on cancer cell metastasis. Science 331: 1559-1564, 2011.

4. Chiang AC and Massagué J: Molecular basis of metastasis. N Engl J Med 359: 2814-2823, 2008.

5. Chambers AF, Groom AC and MacDonald IC: Dissemination and growth of cancer cells in metastatic sites. Nat Rev Cancer 2: 563-572, 2002.

6. Stock AM, Troost G, Niggemann B, Zänker KS and Entschladen F: Targets for anti-metastatic drug development. Curr Pharm Des 19: 5127-5134, 2013.

7. Xiu LJ, Sun DZ, Jiao JP, Yan B, Qin ZF, Liu X, Wei PK and Yue XQ: Anticancer effects of traditional Chinese herbs with phlegm-eliminating properties - an overview. J Ethnopharmacol 172: 155-161, 2015.

8. Shu L, Cheung KL, Khor TO, Chen C and Kong AN: Phytochemicals: cancer chemoprevention and suppression of tumor onset and metastasis. Cancer Metastasis Rev 29: 483-502, 2010.

9. Korkina LG, De Luca C, Kostyuk VA and Pastore S: Plant polyphenols and tumors: from mechanisms to therapies, prevention, and protection against toxicity of anti-cancer treatments. Curr Med Chem 16: 3943-3965, 2009.

10. Yang G and An HJ: $\beta$-sitosteryl-3-O- $\beta$-glucopyranoside isolated from the bark of Sorbus commixta ameliorates pro-inflammatory mediators in RAW 264.7 macrophages. Immunopharmacol Immunotoxicol 36: 70-77, 2014. 
11. Yu T, Lee YJ, Jang HJ, Kim AR, Hong S, Kim TW, Kim MY, Lee J, Lee YG and Cho JY: Anti-inflammatory activity of Sorbus commixta water extract and its molecular inhibitory mechanism. J Ethnopharmacol 134: 493-500, 2011.

12. Bae JT, Sim GS, Kim JH, Pyo HB, Yun JW and Lee BC: Antioxidative activity of the hydrolytic enzyme treated Sorbus commixta Hedl. and its inhibitory effect on matrix metalloproteinase-1 in UV irradiated human dermal fibroblasts. Arch Pharm Res 30: 1116-1123, 2007.

13. Raudonè L, Raudonis R, Gaivelytė K, Pukalskas A, Viškelis P, Venskutonis PR and Janulis V: Phytochemical and antioxidant profiles of leaves from different Sorbus L. species. Nat Prod Res 29: 281-285, 2015

14. Kang DG, Sohn EJ, Lee AS, Kim JS, Lee DH and Lee HS Methanol extract of Sorbus commixta cortex prevents vascular inflammation in rats with a high fructose-induced metabolic syndrome. Am J Chin Med 35: 265-277, 2007.

15. Sohn EJ, Kang DG, Mun YJ, Woo WH and Lee HS: Anti-atherogenic effects of the methanol extract of Sorbus cortex in atherogenic-diet rats. Biol Pharm Bull 28: 1444-1449, 2005.

16. Sohn EJ, Kang DG, Choi DH, Lee AS, Mun YJ, Woo WH, Kim JS and Lee HS: Effect of methanol extract of Sorbus cortex in a rat model of L-NAME-induced atherosclerosis. Biol Pharm Bull 28: 1239-1243, 2005

17. Lee SO, Lee HW, Lee IS and Im HG: The pharmacological potential of Sorbus commixta cortex on blood alcohol concentration and hepatic lipid peroxidation in acute alcohol-treated rats. J Pharm Pharmacol 58: 685-693, 2006.

18. Na M, Kim BY, Osada H and Ahn JS: Inhibition of protein tyrosine phosphatase 1B by lupeol and lupenone isolated from Sorbus commixta. J Enzyme Inhib Med Chem 24: 1056-1059, 2009.

19. Nikolaienko RM, Agyekum B and Bouyain S: Receptor protein tyrosine phosphatases and cancer: new insights from structural biology. Cell Adhes Migr 6: 356-364, 2012.

20. Ostman A, Hellberg C and Böhmer FD: Protein-tyrosine phosphatases and cancer. Nat Rev Cancer 6: 307-320, 2006.

21. Liu H, Kato Y, Erzinger SA, Kiriakova GM, Qian Y, Palmieri D, Steeg PS and Price JE: The role of MMP-1 in breast cancer growth and metastasis to the brain in a xenograft model. BMC Cancer 12: 583, 2012.

22. Choi HJ, Chung TW, Kim JE, Jeong HS, Joo M, Cha J, Kim CH and Ha KT: Aesculin inhibits matrix metalloproteinase-9 expression via p38 mitogen activated protein kinase and activator protein 1 in lipopolysachride-induced RAW264.7 cells. Int Immunopharmacol 14: 267-274, 2012

23. Kim JR and Kim CH: Association of a high activity of matrix metalloproteinase-9 to low levels of tissue inhibitors of metalloproteinase-1 and -3 in human hepatitis B-viral hepatoma cells. Int J Biochem Cell Biol 36: 2293-2306, 2004.

24. Vandooren J, Van den Steen PE and Opdenakker G: Biochemistry and molecular biology of gelatinase B or matrix metalloproteinase-9 (MMP-9): the next decade. Crit Rev Biochem Mol Biol 48: 222-272, 2013

25. Kessenbrock K, Plaks V and Werb Z: Matrix metalloproteinases: regulators of the tumor microenvironment. Cell 141: 52-67, 2010.

26. Deng L, Chen N, Li Y, Zheng H and Lei Q: CXCR6/CXCL16 functions as a regulator in metastasis and progression of cancer. Biochim Biophys Acta 1806: 42-49, 2010.

27. Chatterjee S, Behnam Azad B and Nimmagadda S: The intricate role of CXCR4 in cancer. Adv Cancer Res 124: 31-82, 2014.

28. Mehlen P and Puisieux A: Metastasis: a question of life or death. Nat Rev Cancer 6: 449-458, 2006.

29. Chen K, Zhang S, Ji Y, Li J, An P, Ren H, Liang R, Yang J and $\mathrm{Li}$ Z: Baicalein inhibits the invasion and metastatic capabilities of hepatocellular carcinoma cells via down-regulation of the ERK pathway. PLoS One 8: e72927, 2013.

30. Lou L, Ye W, Chen Y, Wu S, Jin L, He J, Tao X, Zhu J, Chen X, Deng A, et al: Ardipusilloside inhibits survival, invasion and metastasis of human hepatocellular carcinoma cells. Phytomedicine 19: 603-608, 2012

31. Wei PL, Tu CC, Chen CH, Ho YS, Wu CT, Su HY, Chen WY, Liu JJ and Chang YJ: Shikonin suppresses the migratory ability of hepatocellular carcinoma cells. J Agric Food Chem 61 : 8191-8197, 2013

32. Chien ST, Lin SS, Wang CK, Lee YB, Chen KS, Fong Y and Shih YW: Acacetin inhibits the invasion and migration of human non-small cell lung cancer A549 cells by suppressing the p38a MAPK signaling pathway. Mol Cell Biochem 350: 135-148, 2011.
33. Chung TW, Moon SK, Chang YC, Ko JH, Lee YC, Cho G, $\mathrm{Kim} \mathrm{SH}, \mathrm{Kim} \mathrm{JG}$ and Kim CH: Novel and therapeutic effect of caffeic acid and caffeic acid phenyl ester on hepatocarcinoma cells: complete regression of hepatoma growth and metastasis by dual mechanism. FASEB J 18: 1670-1681, 2004.

34. Chung TW, Lee YC and Kim CH: Hepatitis B viral HBx induces matrix metalloproteinase-9 gene expression through activation of ERK and PI-3K/AKT pathways: involvement of invasive potential. FASEB J 18: 1123-1125, 2004

35. Bauvois B: New facets of matrix metalloproteinases MMP-2 and MMP-9 as cell surface transducers: outside-in signaling and relationship to tumor progression. Biochim Biophys Acta 1825: 29-36, 2012.

36. Lee JY, Chung TW, Choi HJ, Lee CH, Eun JS, Han YT, Choi JY, Kim SY, Han CW, Jeong HS, et al: A novel cantharidin analog $\mathrm{N}$-benzylcantharidinamide reduces the expression of MMP-9 and invasive potentials of Hep3B via inhibiting cytosolic translocation of HuR. Biochem Biophys Res Commun 447: 371-377, 2014.

37. Ieranò C, Santagata S, Napolitano M, Guardia F, Grimaldi A, Antignani E, Botti G, Consales C, Riccio A, Nanayakkara M, et al: CXCR4 and CXCR7 transduce through mTOR in human renal cancer cells. Cell Death Dis 5: e1310, 2014.

38. Xia Y, Yan J, Jin X, Entman ML and Wang Y: The chemokine receptor CXCR6 contributes to recruitment of bone marrow-derived fibroblast precursors in renal fibrosis. Kidney Int 86: 327-337, 2014.

39. Voermans C, Anthony EC, Mul E, van der Schoot E and Hordijk P: SDF-1-induced actin polymerization and migration in human hematopoietic progenitor cells. Exp Hematol 29: 1456-1464, 2001

40. Ganju RK, Brubaker SA, Meyer J, Dutt P, Yang Y, Qin S, Newman W and Groopman JE: The alpha-chemokine, stromal cell-derived factor-1alpha, binds to the transmembrane G-protein-coupled CXCR-4 receptor and activates multiple signal transduction pathways. J Biol Chem 273: 23169-23175, 1998.

41. Sameermahmood Z, Balasubramanyam M, Saravanan T and Rema M: Curcumin modulates SDF-1alpha/CXCR4-induced migration of human retinal endothelial cells (HRECs). Invest Ophthalmol Vis Sci 49: 3305-3311, 2008.

42. Qian Y, Corum L, Meng Q, Blenis J, Zheng JZ, Shi X, Flynn DC and Jiang BH: PI3K induced actin filament remodeling through Akt and p70S6K1: implication of essential role in cell migration. Am J Physiol Cell Physiol 286: C153-C163, 2004.

43. Simon C, Simon M, Vucelic G, Hicks MJ, Plinkert PK, Koitschev A and Zenner HP: The p38 SAPK pathway regulates the expression of the MMP-9 collagenase via AP-1-dependent promoter activation. Exp Cell Res 271: 344-355, 2001.

44. Popik W and Pitha PM: Early activation of mitogen-activated protein kinase kinase, extracellular signal-regulated kinase, p38 mitogen-activated protein kinase, and c-Jun N-terminal kinase in response to binding of simian immunodeficiency virus to Jurkat $\mathrm{T}$ cells expressing CCR5 receptor. Virology 252: 210-217, 1998.

45. Hosokawa Y, Hosokawa I, Ozaki K, Nakae H and Matsuo T: Human gingival fibroblasts express functional chemokine receptor CXCR6. Clin Exp Immunol 156: 413-418, 2009.

46. Liu YL, Huang CC, Chang CC, Chou CY, Lin SY, Wang IK, Hsieh DJ, Jong GP, Huang CY and Wang CM: Hyperphosphate-induced myocardial hypertrophy through the GATA-4/NFAT-3 signaling pathway is attenuated by ERK inhibitor treatment. Cardiorenal Med 5: 79-88, 2015.

47. Mirzapoiazova T, Kolosova IA, Romer L, Garcia JG and Verin AD: The role of caldesmon in the regulation of endothelial cytoskeleton and migration. J Cell Physiol 203: 520-528, 2005.

48. Eckhardt BL, Francis PA, Parker BS and Anderson RL: Strategies for the discovery and development of therapies for metastatic breast cancer. Nat Rev Drug Discov 11: 479-497, 2012.

49. Jiang YL and Liu ZP: Natural products as anti-invasive and anti-metastatic agents. Curr Med Chem 18: 808-829, 2011.

50. Jones V and Katiyar SK: Emerging phytochemicals for prevention of melanoma invasion. Cancer Lett 335: 251-258, 2013. 